\title{
Hacia una teoría política crítica
}

$H$ ay que convencerse de que la palabra "política" no es una mala palabra. No denota únicamente los manejos estratégicos de los políticos ni la "voluntad popular expresada en las urnas". Y tampoco debe asustarnos si se la define como "el arte de lo posible", a no ser que seamos de ésos cuya famélica imaginación seguirá siendo su única fuente de posibles. Mas aún, no sólo se trata de que nuestras nociones de política se transformen, sino de que lo haga la misma praxis, que no puede dejar de ser política. El esfuerzo por compartimentar es comprensible, pero el de articular en una noción de totalidad - que no es lo mismo que totalitarismo o totalización - no sólo lo es también, sino que es necesario y, más aún, urgente. Si siempre será de utilidad designar mediante "la política" aquellas acciones que unos agentes determinados realizan, también se hace necesario politizar más y más órbitas de nuestra vida, de manera que éstas puedan nutrir proyectos reales, precisamente porque se trataría de "posibles".

Esta tarea de politizar los distintos ámbitos del mundo de la vida era algo con lo que sintonizaba muy bien Karl Marx. En su visión del ser humano, de 
la naturaleza y del orden de lo real, no cabía suponer una separación entre "regiones de la realidad", a no ser únicamente como principio metodológico de análisis. ¿Suena extraña esta afirmación? Naturalmente. Más de un siglo de "marxistas" se encargaron de poner el énfasis en la idea contraria, la que di-secciona la realidad en compartimientos estancos - estructura y superestructura, economía e ideología, materialismo e idealismo - y construye mecanismos de "conversión" o "reflejo", con los que podríamos tener acceso a la sociedad de la manera como lo tiene el cirujano o el carnicero. Y este último giro en la metáfora de las profesiones no es un mero uso estilístico. Hasta qué punto las carnicerías estalinistas - y las que ahora efectúa el capitalismo imperial-son inseparables de esa manera de entender el ejercicio crítico es más que un tema de investigación interesante. Efectivamente, podríamos decir que una concepción empirista y mecanicista de los fenómenos sociales ha emigrado de un lado a otro del espectro ideológico y no ha dejado de hacerlo aún ahora. Ni "empirismo" es sinónimo de científico burgués ni mecanicismo lo es de los profesores soviéticos. Si no lo creemos, echemos un vistazo a los denodados esfuerzos por convertir la dialéctica en una versión de la regla de tres - "tres estadios", "tres dimensiones", "tres momentos" - o en los empeños más recientes en reducir la política a mediciones de preferencias y proyección de "resultados". Cabe sospechar que existen intimas y obscenas relaciones entre los apparatchik y muchos de los actuales politólogos.

Por otro lado, el sentido en el que Marx era un crítico es inseparable de su compromiso político. Que se haya equivocado en algunos de sus análisis o que sus esperanzas puestas en determinada clase social, el proletariado, se hayan visto oscurecidas por los acontecimientos es una cosa, pero otra cuestión muy diferente es que nos dejara como legado un paradigma perfectamente válido para el ejercicio de la labor de investigación sobre lo social: no hay investigación social sin un compromiso específico. En Marx, esto específico es radicalmente específico, es decir, es un compromiso de clase. Asunto peliagudo como los hay, sobre todo al recordar que el mismo Marx podía haber sido cualquier cosa menos un proletario. Pero el que esto genere problemas y posibles contradicciones no es argumento de refutación absoluta. Más importante es la pregunta que la propuesta marxiana nos suscita: ¿es inocente la labor de investigación social? Tampoco tiene mucho valor decir que esto se refiere a la "ciencia social" pero no a la "ciencia política", ya que lo que objetamos precisamente es que esta última haya asumido las muy cuestionables directrices de objetividad y neutralidad valorativa pregonadas desde la 
primera - recordemos a Max Weber-y, peor aún, que tal desplazamiento se construya sobre algún tipo de ignorancia de lo que la política ha significado usualmente. No sólo es que una simple reflexión histórica nos sitúa sobre la evolución de un concepto y una práctica evidentemente ligados a intereses concretos de los individuos que los actualizan; yendo más allá, al confrontar las conclusiones supuestamente asépticas que los "analistas políticos" dicen extraer de los "hechos", es imposible resistir a la tentación de hacerles preguntas acerca de lo que rompe la "simplicidad denotativa" o la "neutralidad ideológica" de sus afirmaciones: ¿qué valores subyacen a las expresiones como "gobernabilidad", "polarización", "sustentabilidad"?

A estas preguntas de índole más bien "semántica", en donde cuestionamos la coherencia interna de las afirmaciones, podríamos agregar otras en las que el asunto se muestra aún más interesante: ¿qué motivos se esconden tras la indagación?, ¿cuáles son las consecuencias de las afirmaciones que se realizan acerca de la realidad? Evidentemente, la pragmática no es piadosa con los neutrales, más aún si se adscriben a alguna clase de significado de la expresión "política". ¿No fue el mismo Weber quien nos decía que la responsabilidad por las consecuencias sería el nuevo paradigma que vendría a sustituir a una anacrónica ética de la convicción? Como bien lo señala Franz Hinkelammert, este criterio dará pie a una curiosa contradicción en sus postulaciones metodológicas, ya que siendo ésta la única lógica que vuelve sostenibles sus críticas al socialismo de la economía planificada - mientras los socialistas introducen valores en sus pronósticos y planes, los defensores del capitalismo sólo se limitan a dejar que las cosas funcionen tal cual son, etc. - , resulta que la acusación de irresponsabilidad, de los socialistas, sólo tiene sentido si la crítica introduce valores internos al funcionamiento del sistema - performatividad, eficacia, eficiencia - y, cuestión aún más grave, si se reconocen valores externos al sistema mismo, como el que éste no debe acabar con las mismas condiciones que lo hacen posible: la cultura, el bienestar de la sociedad, la supervivencia de la humanidad...

Esto último nos permite volver a Karl Marx y abundar un poco más en torno al carácter crítico de su teoría. Como factor de contraste, podemos adoptar la definición implícita que utiliza Norman (Ron Perlman), el predicador en la cinta de Stacy Title, The Last Supper, cuando se refiere a la crítica (criticism) que ejercían personas como Paine, Jefferson y Monroe: éstos eran críticos en tanto expresaban y hacían valer racional y argumentativamente sus ideas frente a un conjunto amplio de interlocutores. Ni hablar, Marx suscribiría alegremente tal definición, pero sólo 
si tal ejercicio crítico estuviera fundado en una noción aún más radical: "La crítica no arranca de las cadenas las flores imaginarias para que el hombre soporte las sombrías y escuetas cadenas, sino para que se las sacuda y puedan brotar las flores vivas... Y la teoría es capaz de apoderarse de las masas cuando argumenta y demuestra ad hominem, cuando se hace radical. Ser radical es atacar el problema por la raíz. Y la raíz, para el hombre, es el hombre mismo... En un pueblo, la teoría sólo se realiza en la medida en que es la realización de sus necesidades" (La sagrada familia, 1845). Es claro el punto de Marx: no se trata de oponer cualquier idea, sino de aquellas que conectan con las cadenas, con la miseria humana. Pero tampoco es que deban conectar de cualquier manera, sino que deberán estar unidas a la lucha en función del rompimiento de esas cadenas, la superación de dicha miseria. Ése será el norte de la investigación del científico y de la praxis política: la emancipación de esa humanidad que sufre en su propia carne y ve frustradas sus capacidades, su subjetividad. Aclarar qué habríamos de tomar en cuenta en concreto y qué sería mejor no suponer en esta tarea es a lo que Marx dedicó su vida, desarrollando su crítica en El manifiesto comunista (1848), en los Grundrisse (1857-1858) y en El capital (1867-1883), pero sin perder los bríos juveniles y la irreverencia que nos regala en su tesis doctoral (1841) y en los Manuscritos económicos-filosóficos (1844).

Para una teoría política crítica, la garantía de que el método es el adecuado no radica en la abundancia de planteamientos "elegantes" o en la búsqueda de "simplicidad teórica", sino en continuar comprometidos con la liberación de los que padecen la explotación, la inhumanidad y la exclusión. Reconstituir políticamente la crítica es proceder desde y para el ser humano, en el peculiar sentido que le imprime Marx. Para ser críticos, no es que "debamos" ser marxistas, pero, en mayor o en menor medida, ya somos marxianos, es decir, nuestra actividad teórica y nuestras acciones en la práctica política reflejan ya un posicionamiento dentro de las redes de compromisos que los individuos y colectivos construyen alrededor de sí mismos. Y podemos ser aún más marxianos si, en lugar de limitarnos simplemente a reconocer nuestra situación, tomamos posición en favor de los que padecen la miseria y la deshumanización. Esto va más allá de un mero romanticismo, aunque sí tiene un fuerte componente idealista. Es que se requiere idealismo para imaginar los posibles desde los que habrá que pensar y construir la sociedad en la que ya no haya inhumanidad. Ni más ni menos. Oscar Wilde decía que, respecto a la naturaleza humana, lo único seguro era el cambio; y allí encontraba una buena razón para exaltar el papel político de las artes y 
la literatura, precisamente porque hablan del futuro, de cosas irreales e imposibles porque aún no se han hecho presentes. Lo que pasa es que la única manera de pensar lo posible es contra el telón de fondo de lo que contradice los más elementales reparos "prácticos". Lo que todavía no está debe aparecer ante nuestros ojos si queremos que el cambio se dé al fin.

Haciendo un uso (bastante) libre de la terminología aristotélica, diremos que si la política (praxis) es el arte de lo posible, este posible sólo se vislumbra en la actividad imaginativa (poiesis) que no teme pensar en un mundo en el que quepan muchos mundos (Hinkelammert). Pero ya lo decía el Estagirita: a diferencia de la poiesis, sólo la praxis realiza su fin en sí misma. Nosotros podemos interpretar esto último como constante distanciamiento y llamado de atención crítico, frente a todo proyecto de perfeccionamiento humano o modelo de construcción de la buena sociedad. Y sólo de esta manera la crítica volverá a ocupar una auténtica posición. Asimismo, es el modo como la teoría política podrá ir más allá de un raquítico cálculo mercadológico de opiniones y preferencias. 